\title{
Enablers and Inhibitors of SISP: A Case Study of a Korean Large Corporation
}

\author{
Jungho Yang, Kerry Tanner and Joze Kuzic \\ Monash University, Caulfield East, Melbourne, Victoria, Australia
}

\begin{abstract}
Within more turbulent, and increasingly globalized and digitalized environments, Strategic Information Systems Planning (SISP) has long been recognized as one of the most significant factors for better management. More recently, SISP has been included as one of the important components of IT governance frameworks. However, as business environments and IS/IT applications are rapidly growing in complexity, SISP needs to be implemented rigidly enough to meet project requirements, yet sufficiently flexible to adjust to environmental and managerial change. To diminish the problems and develop a successful SISP process, various enablers that make change possible both inside and outside of the corporation need to be identified and enhanced, and all possible inhibitors that prevent corporations from obtaining benefits and value need to be predicted and minimized. Besides, the inhibitors and enablers are intimately interrelated with each other. This paper presents a model of these interrelationships and reports on a pilot case study that investigated enablers and inhibitors of SISP in a large Korean corporation. The study demonstrated close relationships between enablers and inhibitors and benefits of SISP. Further research is planned to validate these findings in other large Korean corporations.
\end{abstract}

Keywords: Strategic Information Systems Planning (SISP), IT Governance, Enablers, Inhibitors

\section{Introduction}

In today's increasingly dynamic knowledge and information based economy, information systems (IS) and information technology (IT) have become crucial in the support, sustainability and growth of business. Furthermore, the recent business paradigm has moved from management into governance to improve accountability, leadership, organizational processes, structures, and even human resources of a Copyright (C) 2011 Jungho Yang, Kerry Tanner, and Joze Kuzic. This is an open access article distributed under the Creative Commons Attribution License unported 3.0, which permits unrestricted use, distribution, and reproduction in any medium, provided that original work is properly cited. Contact author: Jungho Yang E-mail: Jungho.Yang@infotech.monash.edu.au corporation through the link between IS/IT and the present/future business objectives and strategies (Peterson, 2004; Sohal and Fitzpatrick, 2002; Ward and Peppard, 2002). Accordingly, corporations have long invested considerable time and resources into developing IT, and as well have developed Strategic Information Systems Planning (SISP). SISP has steadily provided diverse benefits for corporations since the 1980s, to improve their overall performance. 
As business environments and IS/IT applications are rapidly growing in complexity, the choice of an SISP method has been a critical issue on the management agenda. Furthermore, much of the existing SISP has proven inadequate to handle the latest IT issues, including capability, collaboration, competency, and flexibility. Therefore, SISP needs to be implemented rigidly enough to enable the completion of a project, yet flexibly enough to adjust to environmental and managerial change. In order to diminish the problems and to develop a successful SISP process, top executives need to address and consider significant variables, including enablers and inhibitors of SISP. Various enablers that make change possible both inside and outside of the corporation need to be enhanced, and potential inhibitors that could prevent corporations from obtaining benefits and value need to be predicted and minimized when SISP is implemented, thereby decreasing the failure rate.

The primary focus of this research is to identify enablers and inhibitors of SISP to maximize benefits and value for corporations. This paper proposes a model for SISP to describe the interrelationships between inhibitors, enablers and benefits of SISP, and tests this model with a pilot case study of a Korean corporation. The next section reviews the theoretical perspectives of SISP and IT governance as well as their interrelationships. Section 3 examines literature pertaining to the inhibitors, enablers and benefits of SISP, while Section 4 proposes a model of their interrelationships. Section 5 presents the findings of the pilot case study, and Section 6 draws conclusions and identifies areas of future research.

\section{Literature Review}

\subsection{Strategic Information Systems Planning (SISP)}

As IS/IT has become a strategic tool that enables corporations to accomplish their mission and objectives, strategic information systems planning (SISP) has been regarded as a critical issue on the management agenda since the 1980s (Doherty et al., 1999). Additionally, definitions of SISP have been changed and modified in diverse ways by a number of authors. Lederer and Sethi (1988, p. 446) defined SISP as the process of identifying a portfolio of computer-based applications that will assist a corporation in executing its business plans and consequently realizing its business goals.' It has also been argued that the definition of SISP can be summarized as being a process of identifying a portfolio of computer-based applications that will assist a corporation in executing its business plans and achieving its business goals through aligning IS strategy with business strategy and creating an advantage over competitors (Doherty et al., 1999; Earl, 1993; Reich and Benbasat, 2000).

The primary objectives of SISP are to align organizational IS/IT investment and business strategy with an IS/IT strategy and to utilize IS/IT for creating and sustaining a corporation's strategic competitive advantage by integrating, coordinating, controlling and implementing the IT resources (Chi et al., 2005; Earl, 1993; Grover and Segars, 2005; Pai, 2006). Additionally, with the rapid advancement and change of both IS/IT and business environments in the last few years, a SISP process involves major changes for corporations, including defining new business strategies, technologies, policies and architectures; improving 
adaptability to align IS and business strategies; enhancing the capabilities of existing internal and external systems; increasing flexibility of organizational and environmental changes; and improving cooperation among managers, other users and systems developers (Chi et al., 2005; Hartono et al., 2003; Pant and Hsu, 1999; Ward and Peppard, 2002).

Therefore, SISP is an exercise or ongoing activity that enables corporations to develop priorities for IS/IT development and helps them reach their goals of improved competitiveness, efficient operations, and effective resource and risk management.

\subsection{IT Governance}

Amidst the challenges and changes of the 21st century, IT governance is high on the agenda and most corporations have focused on IT governance to pursue gains in efficiency and meet accountability and compliance requirements (De Haes and Van Grembergen, 2009; Lee et al., 2008; Symons, 2005b; Willson and Pollard, 2009). However, it is surprising that there is still not a generally accepted definition of IT governance--a variety of IT governance definitions have been proposed:

- 'The responsibility of the board of directors and executive management. It is an integral part of Enterprise Governance and consists of the leadership and organizational structures and processes that ensure that the organization's IT sustains and extends the organization's strategies and objectives' (IT Governance Institute, 2003).

- 'Specifying the decision rights and accountability framework to encourage desirable behaviour in the use of IT' (Weill and Ross, 2004).

- 'The organizational capacity exercised by the board, executive management and IT management to control the formulation and implementation of IT strategy and in this way ensure the fusion of business and IT' (Van Grembergen et al., 2004).

- 'The system by which an organization's IT portfolio is directed and controlled. It describes (a) the distribution of IT decision-making rights and responsibilities among different stakeholders in the organization, and (b) the rules and procedures for making and monitoring decisions on strategic IT concerns' (Peterson, 2004).

- 'The strategic alignment of IT with business such that maximum business value is achieved through the development and maintenance of effective IT control and accountability, performance management and risk management' (Webb et al., 2006).

The primary goal of IT governance is to achieve a better alignment between the business and IT. Several authors also argued that much of the existing literature has often approached the topic of IT governance by describing and categorizing existing or proposed structures, processes or relational mechanisms (control frameworks or communications) and the elements that are important to implement good IT governance (De Haes and Van Grembergen, 2009; Symons, 2005b; Willson and Pollard, 2009). IT governance is considered a much concept than IT management, focused on performing and transforming IT to 
meet present and future demands of the business (internal focus) and business customers (external focus) (Peterson, 2004; Sohal and Fitzpatrick, 2002).

A number of IT governance frameworks have been developed, such as the Control Objectives for Information and related Technology (COBIT), IT Infrastructure Library (ITIL) and Capability Maturity Model Integration (CMMI). However, arguably the best known and most frequently used framework is COBIT (Abu-Musa, 2009). As a comprehensive framework, COBIT provides important guidelines for IT governance, providing corporations with a useful tool to start evaluating their IT governance systems, and a toolset that allows IT managers to bridge the gap between control requirements, technical issues and business risks.

IT governance has become more prominent and developing an effective IT governance structure is critical. It harmonizes decisions about the management and use of IT with desired behaviours and business objectives (Weill and Ross, 2004). Without carefully designed and implemented governance structures, corporations will leave this harmony to chance.

\subsection{The relationship between IT Governance and SISP}

Strategic information systems (SIS) has been a predominant area of influence on the emergence of IT governance. The primary objectives for developing both SISP and IT governance are similar.

Webb et al (2006) claim that the concept of IT governance began to emerge from within the discussion of strategic planning and management. Several researchers also argue that the literature on IT governance has greatly drawn from a SIS background, and that there are considerable links and areas of overlap between IT governance and both strategic information systems (SIS) and strategic information systems planning (SISP) as a research discipline (ISACA, 2008; Musson, 2009; Willson and Pollard, 2009). For example, SISP has widely been adopted as a method for accomplishing IT/business alignment (Gartlan and Shanks, 2007; Luftman et al., 2009; Reich and Benbasat, 2000) and such alignment is one of the key factors of successful SISP (Earl 1993; Krell and Matook, 2009; Newkirk et al., 2008; Pai, 2006). A key goal and outcome of IT governance is strategic alignment, and achieving a better alignment between business and IT begins and ends with good IT governance (De Haes and Van Grembergen, 2009; Symons, 2005a). Accordingly, Webb et al (2006) argue that it is reasonable to suggest that IT governance differs from SIS or SISP in terms of its emphasis.

Parfitt and Tryfonas (2009) claimed that having defined IT governance, there is a need to know Earl's (1993) four key areas of SISP, including: (1) aligning investment in IS with business goals; (2) exploiting IT for competitive advantage; (3) directing efficient and effective management of IT resources; and (4) developing technology policies and architectures. Intervening research since Earl's work (1993) has placed increasing emphasis on risk management and performance management, but with these two exceptions, his key areas have proved very stable. Furthermore, it has widely known that an IT governance framework can be deployed using a mixture of various structures, processes and relational mechanisms (Peterson, 2004; Weill and Ross, 
2004). Van Grembergen et al (2004) assert that the necessary elements of SISP can be adopted as one of the important processes of an IT governance framework. In particular, COBIT, the most popular IT governance framework in the world, includes strategic planning for IS/IT and business as one of its key domains. Cassidy (2006) argues that governance is a central framework that should be in place for an SISP process to be successful and that SISP is a very significant component to effective governance.

As a consequence, SISP could be used as a key process of an IT governance framework to deal with the chief issues of a corporation. The key factors of SISP enable corporations to enhance operational efficiency and to set up an effective IT governance framework. For corporations to succeed in SISP, it is important to be alert to key enablers, inhibitors and benefits of SISP.

\section{Inhibitors, enablers and benefits of SISP}

\subsection{Inhibitors of SISP}

In undertaking research on SISP, investigators typically conduct a major and intensive multi-phase study within the highest level of a corporation over a long time frame. However, a number of surveys have noted considerable dissatisfaction with SISP projects set up to achieve corporate goals and objectives (Basu et al., 2002; Choi and Bae, 2007; Earl, 1993; Hartono et al., 2003; Pant and Hsu, 1999; Teo and Ang, 2001). The failure to effectively execute SISP could cause lost opportunities, duplicate effort, create incompatible systems and result in wasted resources (Earl, 1993; Hartono et al., 2003; Pant and Hsu, 1999). Thus, it can ultimately cause corporations to lose competitive advantage.
Earl (1993) noted that the most common unsuccessful features of SISP include resource constraints, SISP not being fully implemented, deficiency of top management acceptance, length of time involved and poor user/IS relationships. Min et al (1999) suggested that SISP methodology problems are the cause of the low rate of SISP implementation, for example, inadequacy of support for information technology architecture (ITA), under-emphasis on IT opportunities, duration of SISP and lack of support for business process reengineering (BPR). Several researchers asserted that the high failure rate of SISP in business has been long regarded as largely a result of a managerial factors rather than technical factors (Chi et al., 2005; Hartono et al., 2003; Griffiths and Hackney, 2001; Palanisamy, 2005; Pant and Hsu, 1999; Ward and Peppard, 2002). They suggested that the main causes of failure as follows:

- Limited planners' knowledge;

- Lack of top management support and understanding;

- A lack of user commitment to projects;

- A poor level of communication between users and IS staff;

- Longer time and planning horizon;

- Serious cost budget overruns due to insufficient understanding of the work necessary to deliver the project; and

- Poorly defined and integrated business objectives caused by inadequate appreciation of the business's needs.

Furthermore, it has been claimed that existing SISP systems have significant limitations-such as failure to adequately support an information architecture 
(Palanisamy, 2005), inability to deal with the high unpredictability and diversity of the environment change (Newkirk and Lederer, 2006), and inadequacy of handling integrated views of the entire corporation in current business practice (Jonkers et al., 2006). Choi and Bae (2007) indicated that the current SISP systems still lack the capabilities to systematically support sophisticated strategic planning processes. For the reasons given above, several authors have emphasized that there is no one methodology that is superior to another in all situations regardless of techniques or related products (Cerpa and Verner, 1998; Hartono et al., 2003; Palanisamy, 2005).

It is important to understand that most of the foregoing problems and barriers in SISP have originated in business strategy rather than technical strategy. To obtain maximum benefits from SISP, corporations must not underestimate the impact of the inhibitors and issues mentioned above.

\subsection{Enablers of SISP}

It has been widely noted that SISP success can be viewed along two dimensions--the degree of attainment of the objectives of SISP and improvement in the capability of the planning system (Kunnathur and Shi, 2001; Segars and Grover, 1998). A number of authors have also revealed successful key factors in SISP applications. Earl (1993) presented five success factors in SISP, including top management involvement, top management support, business strategy available, study business before technology, and good IS management. Segars and Grover (1998) developed four dimensions to assess SISP success, including alignment, analysis, cooperation, improvement of capability. These four dimensions have subsequently been utilized as the basis for the assessment of SISP success by several researchers (Grover and Segars, 2005; Kunnathura and Shi, 2001; Newkirk and Lederer, 2006).

The success of SISP is a function of many variables. Cerpa and Verner (1998) assert that organizational commitment, senior management and team involvement have a significant association with the quality of SISP. Gottschalk (1999) emphasized that there are important factors to develop successful SISP, such as user involvement including user participation support, training, and understanding; analysis of the corporation; anticipated changes in the external environment; and solutions to potential resistance. King (2000) also argued there are some significant enablers of SISP, including senior management involvement both in the planning process and in the implementation of plans; user involvement in the planning process; and the comprehensive of the IS plan. Hence, more commitment and involvement should produce greater success and have a positive impact on the achievement of SISP in the rapidly changing business and IT environment (Basu et al., 2002; Cassidy, 2006; Pai, 2006). In particular, in accordance with the increasing importance of involvement and commitment of the corporation on SISP project, organizational learning has continuously been recognized and regarded as one of the success factors to implement SISP and to improve the effects of IS/IT competences and capabilities on a corporation's performance (Audy and Lederer, 2000; Wang and Tai, 2003). Therefore, Hartono et al (2003) stress that SISP has now been evolving as a knowledge management (KM) activity.

Several authors claim that the existing SISP models are inadequate in the support for 
both enterprise architecture (EA) and business process reengineering (BPR)-in terms of their inability to deal with integrated views of the entire corporation; to improve the capabilities and flexibilities; and to systematically support sophisticated SISP processes (Attaran, 2004; Choi and Bae, 2007; Jonkers et al., 2006; Min et al., 1999; Palanisamy, 2005; Ward and Peppard, 2002). As the business and the IT environment has changed rapidly and unpredictably, achieving SISP success has become not only more critical but also more difficult. Several researchers have investigated the relationship between environmental issues and SISP success and proposed that more comprehensive or extensive SISP in an uncertain environment will be able to produce greater success (Chi et al., 2005; Newkirk and Lederer, 2006). Basu, et al (2002) asserted that the studies of different variables have assumed a positive impact of these factors on SISP success, and that greater understanding of the predictor factors could create more foreseeable success.

To sum up, one of the critical factors for successful SISP is the close linkage of the IS strategy and business strategy. The enablers of SISP are also intimately associated with the enhancement of organizational success. This means that effective SISP should help to achieve alignment between IS and business strategies as well as to facilitate cooperation and partnership among managers and user groups of the corporation. It also should encourage corporations to anticipate relevant events and issues by the reduction of possible conflicts that may put SISP implementation at risk, and adapt to unexpected organizational and environmental change.

\subsection{Benefits of SISP}

The effectiveness or success of SISP is typically operationalized in terms of the accomplishment of planning objectives as a single or multi-factor construct ( $\mathrm{Chi}$ et al., 2005; Wang and Tai, 2003). This means that the benefits of SISP cannot be reduced to such simple financial measures as return on investment (ROI), payback, or internal rate of return (Segars and Grover, 1998; Sugumaran and Arogyaswamy, 2004). This is due to SISP, like strategic business planning, produces many difficult-to-assess benefits.

Effective SISP is able to provide diverse benefits and contributions to corporations. It also sustains an enterprise-wide vision; coordinates the efforts of organizational members; diminishes uncertainty and redundancy; prioritizes decision making; and facilitates the use of IS/IT to significantly impact a corporation's strategies (Basu et al., 2002; Palanisamy, 2005). Therefore, it delivers benefits beyond the resources consumed to sustain positive organizational capability and effectiveness. Doherty et al (1999) observed the importance of SISP within the IS literature and pointed out its benefits: (1) facilitating the integration of the IS function within the corporation; (2) supporting the identification of opportunities to use IS/IT for strategic purposes; (3) ensuring that adequate resources are allocated to critical applications; and (4) ensuring that the IS function supports organizational goals and activities at every level.

Teo and Ang (2000) examined the usefulness of SISP by a field survey of IS executives in Singapore. Results indicated that SISP is generally perceived to be useful for supporting business objectives, improving 
systems integration, exploiting IT for competitive advantage, prioritizing IS development projects, and improving top management support for the IS function. More recently, Cassidy (2006) emphasized that there are similarities in the benefits of SISP, even though the reasons driving the development of SISP might be different for each corporation. She proposed that the advantages of SISP are:

- Effective management of an expensive and critical asset of the corporation;

- Improving communication and the relationship between the business and IS department;

- Aligning the IS direction and priorities to the business direction and priorities;

- Identifying opportunities to use technology for a competitive advantage and increase the value to the business;

- Planning the flow of information and processes;

- Efficiently and effectively allocating IS resources; and

- Reducing the effort and money required throughout the life cycle of systems.

It is obvious that effective SISP is able to provide diverse benefits and contributions to corporations. It is available for them to enhance and sustain organizational capability, competency, and flexibility by the identification of the benefits. The benefits can particularly be more than simple financial measures, lead to support business objectives, improve systems integration and exploit IT for competitive advantage, thereby increasing the value to the corporation.

\section{A Preliminary Model of the Interrelationships Between Inhibitors, Enablers and Benefits of SISP}

As mentioned above, most of the existing SISP approaches are not sufficient to achieve a corporation's overall objectives as well as to meet current requirements for capabilities, collaboration, competency, and flexibility. To obtain benefits and success from the development of SISP, corporations need to consider all possible tangible and intangible factors simultaneously. Based on an extensive review of the SISP literature, it was postulated that inhibitors and enablers of SISP are closely interrelated, and that inhibitors could be transformed into enablers.

Figure 1 depicts the close relationship amongst the inhibitors, enablers and benefits of SISP. As shown in the figure, inhibitors of SISP, such as lack of top management commitment and involvement, poorly defined and integrated business objectives and strategy, a deficient level of communication between users and IS staff, and inadequacy of analysis on diverse changes in the external environment etc., can be turned around and expressed in positive terms as critical enablers of SISP, for instance, top management commitment and involvement, well aligned and integrated business objectives and strategy, and effective communication between users and IS staff. 


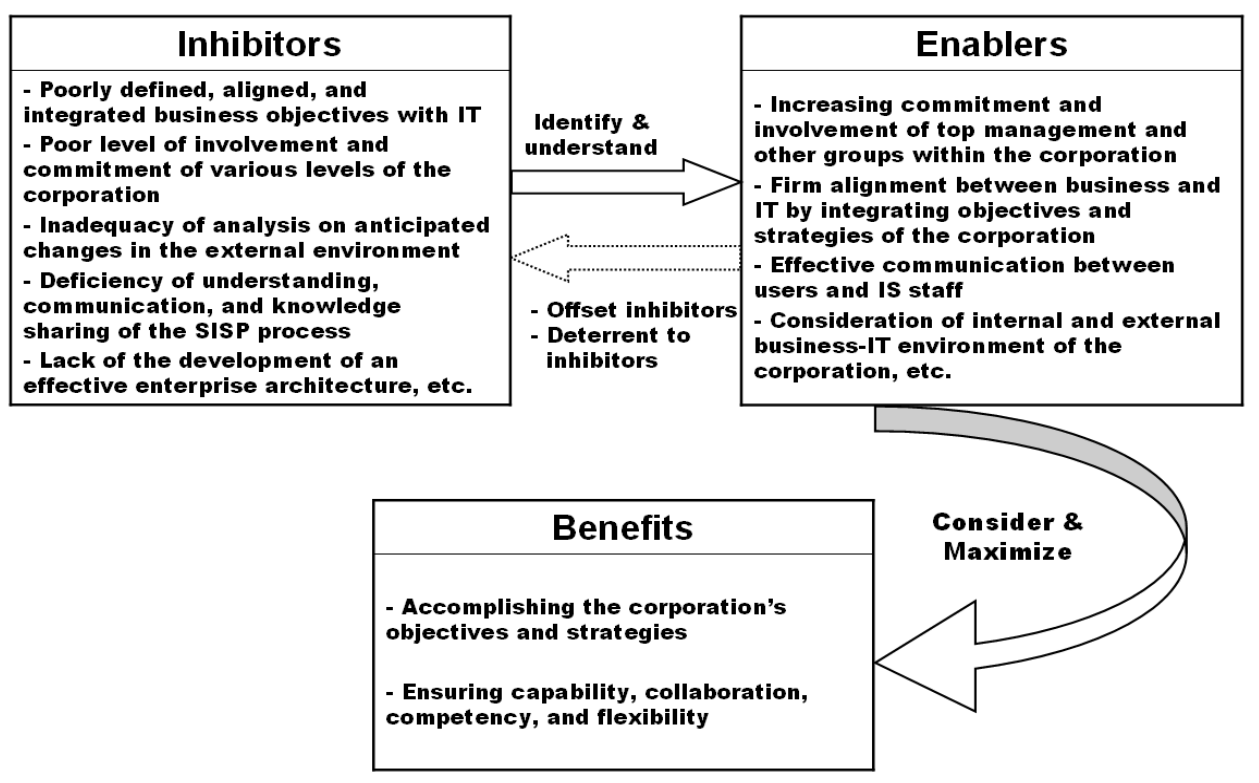

Fig 1. The proposed model for describing the interrelationship inhibitors, enablers and benefits of SISP

Additionally, focusing on maximizing the enablers and minimizing the inhibitors should help ensure greater levels of success with SISP-for example: raising the level of involvement and commitment of various levels of the corporation; solid alignment between business and IT by well-integrated business objectives and strategy; increased communication, knowledge sharing, and understanding of the SISP throughout the corporation; and ensuring the development of an effective enterprise architecture. Corporations would also obtain various benefits and attain their objectives and strategy from the SISP, when they identify and enhance distinct enablers and reduce inhibitors.

Figure 2 is a diagrammatic representation of the proposed research model. This model shows the close interrelationships between inhibitors and enablers of SISP. Potentially inhibitors can be transformed into enablers by their identification and correction or minimization. It is postulated that overcoming inhibitors and enhancing enablers will lead to the realization of benefits from SISP, and in turn to achieving organizational objectives and strategies.

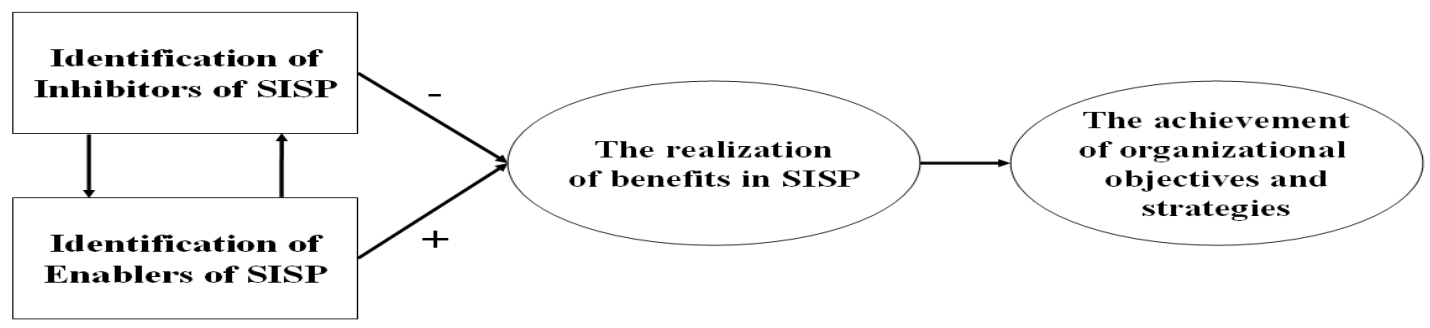

Fig 2. The proposed research model 
Therefore, it could be possible to presume that the three elements, including inhibitors, enablers, and benefits of SISP should closely be related to each other. It is due to that the inhibitors can be transformed into enablers that corporations should positively consider to develop more effective and efficient SISP through the identification and correction of the inhibitors. Furthermore, both identifying enablers and overcoming the inhibitors effectively could ultimately be associated with the way of acquiring diverse organizational benefits and success of the corporation. This means that the enablers of SISP will play an important role in diminishing the inhibitors when a corporation attempts to develop SISP, whereas it will have a positive effect on improving the organizational benefits.

\section{A Pilot Case Study of a Korean Large Corporation}

\subsection{Introduction of SISP in the corporation}

This section presents and describes the current findings of pilot case study interviews conducted with General Manager [IT] and CEO of a large Korean corporation located in Sydney, referred to as "Corporation A." Corporation A is the leading general trading company in Korea. It had established SISP since the branch first started a new business in 2005. The two interviewees stressed that SISP of the head office in Korea and of the branch in Australia are identical, and that the corporation's SISP process is closely linked with its overall corporate governance framework.

\subsection{The inhibitors of SISP in the corporation}

Firstly, the General Manager [IT] stated that the biggest problem that Corporation A confronted in developing SISP was the difficulty of alignment and integration of its entire business information requirements into SISP. In particular, he mentioned that as a consequence of the insufficiency of the alignment and integration, several factors came out as critical ones that need to be resolved in Corporation A, including harmonizing all business requirements into SISP and the enterprise system, and coordinating and sharing information with all members.

Additionally, the GM [IT] indicated that the deficiency of communication and consensus between IT staff and other members was one of the important issues, and he also represented that the insufficiency of interest and understanding on the SISP process was a problem. However, the biggest inhibitor confronted in developing SISP in Corporation A was the practical aspect that is how the corporation can effectively align and integrate the huge and diverse business objectives and requirements into SISP.

However, the CEO in response to the question about the inhibitors of SISP replied as follows: 'Most of the issues and problems that we were faced during the development of SISP have almost been solved and are well reflected in the enterprise system. However, I think that the factors that Corporation A has significantly considered to develop the SISP and enterprise system effectively could be similar to the issues and problems that the corporation should overcome after all.' According to the CEO's answer, the factors 
that Corporation A has recognized to develop SISP successfully would be similar to the inhibitors that they wanted to identify and overcome. This means that inhibitors of SISP can be closely interrelated to enablers as well as the inhibitors could be transformed into enablers. The next section addresses what the enablers of Corporation A are. It also examines whether or not inhibitors could be turned into enablers and vice versa.

\subsection{The enablers of SISP in the corporation}

The two interviewees provided much information on SISP enablers. Similar to the inhibitors, the factors were also diverse and most of the enablers corresponded with the results of the literature review. However, the interviewees had a different perspective on some of the enablers. The summary of SISP enablers is presented in Table 1.

Table 1: The enablers of SISP in Corporation A

\begin{tabular}{|c|c|}
\hline IT General Manager & CEO \\
\hline $\begin{array}{l}\text { 1. The high level of recognition, } \\
\text { participation and support of top } \\
\text { management and executive committees } \\
\text { (Most important) } \\
\text { 2. Understanding various internal and } \\
\text { external environmental factors } \\
\text { 3. The alignment and integration of all data, } \\
\text { information and knowledge in the } \\
\text { corporation } \\
\text { 4. Maintaining and sharing the data, } \\
\text { information and knowledge, including } \\
\text { objectives and visions of the corporation } \\
\text { effectively and efficiently with all members } \\
\text { 5. Organizational learning on SISP process }\end{array}$ & $\begin{array}{l}\text { 1. The high level of recognition, } \\
\text { participation and support of top } \\
\text { management and executive committees } \\
\text { (Most important) } \\
\text { 2. Understanding various internal and } \\
\text { external environmental factors } \\
\text { 3. The alignment and integration of all data, } \\
\text { information and knowledge in the } \\
\text { corporation } \\
\text { 4. Achieving consensus on developing SISP } \\
\text { and the enterprise system by active } \\
\text { communication with all members of the } \\
\text { corporation } \\
\text { 5. Development of a more user-friendly SISP } \\
\text { framework or architecture }\end{array}$ \\
\hline
\end{tabular}

While the first three enablers and most important enabler were the same, the IT General Manager stressed the use and training of the SISP process as user or manager, and the CEO emphasized significant conditions and requirements to develop SISP successfully from the top management perspective.

According to the answers of the GM [IT] and the CEO, Corporation A has considered in developing effective SISP that the most significant enabler was the business viewpoint, that is, the active participation and support of SISP implementation from top management. The high interest and expectation on SISP by top management particularly enabled Corporation A to consider various factors for implementing SISP successfully, including considering internal and external environmental factors, and actively communicating and sharing information and knowledge among all members of the corporation, etc. The requirements also reflected on the alignment and integration of information and knowledge and the development of the enterprise architecture. It enabled Corporation A to ensure business and management transparency, to exchange, receive and share all information conveniently, easily and promptly, and to 
facilitate active communication among all members. Furthermore, the organizational learning on the SISP process contributed to improve the understanding of competences and capabilities on SISP.

Therefore, similar to the inhibitors of SISP, the SISP enablers of Corporation A were also interconnected with other enablers and the factors worked synergistically with other factors. In the next section, the benefits that Corporation A obtained by overcoming and identifying the inhibitors and enablers is addressed.

\subsection{The benefits of SISP in the corporation}

Both the General Manager [IT] and the CEO answered that Corporation A had obtained various advantages and benefits from the effective development of SISP. The CEO emphasized more the business perspective on the benefits, whereas the GM [IT] deliberated on both the business and IT perspectives. The summary of SISP benefits is given in Table 2 .

Table2: The benefits of SISP in Corporation A

\begin{tabular}{|l|l|}
\hline \multicolumn{1}{|c|}{ IT General Manager } & \multicolumn{1}{c|}{ CEO } \\
\hline $\begin{array}{l}\text { 1. The realization of alignment and } \\
\text { integration of information and knowledge of } \\
\text { the corporation (Most significant benefit) }\end{array}$ & $\begin{array}{l}\text { 1. The realization of alignment and } \\
\text { integration of information and knowledge of } \\
\text { 2. Reducing the processing time for an }\end{array}$ \\
$\begin{array}{l}\text { approval } \\
\text { 3. Possible to obtain the past and latest } \\
\text { knowledge and information in real-time }\end{array}$ & $\begin{array}{l}\text { 2. Reducing the time for better and effective } \\
\text { decision-making }\end{array}$ \\
4. Ease of tackling organizational learning & management in the corporation \\
\hline
\end{tabular}

The two interviewees answered that the most critical benefits of SISP in the corporation A was the alignment and integration of all information and knowledge of the corporation. Similarly with the inhibitors and enablers, the most important benefit of SISP also had considerable influence on other benefits. Even though the GM [IT] and CEO had slightly different perspectives on the benefits, they both stressed that Corporation A has gained diverse advantages by their effectively developed SISP. Thus, it is possible to presume that successfully implemented SISP can provide various benefits for corporations through improving the efficiency of overall management, including identifying opportunities for competitive advantage and increasing value.

\section{Conclusion and future research}

Corporations have long invested considerable time and resources into developing IT and SISP to obtain various benefits. Even with increasing emphasis on governance, SISP has continued to be recognized as one of the significant domains and processes of an IT governance framework to improve accountability, processes and structures of the corporation. According to the literature, as business environments and IS/IT applications are rapidly growing in complexity, the choice of a SISP method has long been a critical issue on the management agenda. Therefore, to develop effective and successful SISP, it has been stressed that there is a need to consider and understand the importance of diverse enablers that make change possible both 
inside and outside of the corporation as well as inhibitors of SISP that prevent them from obtaining benefits and value. Based on the consideration of the inhibitors and enablers, corporations will be in a better position to realize various benefits from their SISP. Besides, the inhibitors, enablers and benefits of SISP are closely interrelated. Through the appropriate identification of the existing issues in a corporation, inhibitors can be transformed into enablers to assist in the successful implementation of SISP.

According to the case study interviews with the General Manager [IT] and CEO in Corporation A, several inhibitors, enablers, and benefits of SISP were identified. In particular, there was the most significant inhibitor and enabler that Corporation A wanted to overcome and consider, and they were closely interrelated with other ones. The two interviewees mentioned the inhibitors could be changed as advantages or success factors, if Corporation A well considers and reflects on the factors to implement SISP successfully. They also stressed that the effective development of SISP could have a big impact on creating diverse benefits by improving the efficiency of overall management. By implication, it seems reasonable to assume that all corporations have various inhibitors and enablers that they need to consider, identify and overcome. Even though each corporation has different business processes and structures, they should deliberate on as many inhibitors and enablers as possible to obtain various benefits from SISP.

After completing the pilot case study, further research is planned to validate these findings in other large Korean corporations.

\section{References}

Abu-Musa, A A. (2009) 'Exploring COBIT Processes for ITG in Saudi Organizations: An empirical Study,' The International Journal of Digital Accounting Research, 9, 99-126.

Audy, J. and Lederer, AL. (2000), 'Seven Principles of Organizational Learning in Information System Planning: Preliminary Findings from a Case Study,' Proceedings of the Sixth Americas Conference on Information Systems, Long Beach, CA, 12251229.

Attaran, M. (2004) 'Exploring the relationship between information technology and business process reengineering,' Information and Management, 41 (5), 585596.

Basu, V., Hartono, E., Lederer, AL. and Sethi, V. (2002), 'The impact of organizational commitment, senior management involvement, and team involvement on strategic information systems planning,' Information and Management, 39 (6), 513524.

Cassidy, A. (2006) A Practical Guide to Information Systems Strategic Planning, $2^{\text {nd }}$ edition, Taylor and Francis Group, US.

Cerpa, N. and Verner, JM. (1998), 'Case study: The effect of IS maturity on information systems strategic planning,' Information and Management, 34 (4), 199-208.

Chi, L., Jones, KG., Lederer, AL., Li, P., NewKirk, HE. and Sethi, V. (2005), 'Environmental assessment in strategic information systems planning,' International Journal of Information Management 25 (3), 253-269. 
Choi, S. and Bae, S. (2007), 'Strategic information systems selection with incomplete preferences: a case of Korean electronics company,' Journal of the Operational Research Society, 60 (2), 180190.

De Haes, S. and Van Grembergen, W. (2009), 'An Exploratory Study into IT Governance Implementation and its impact on Business/IT Alignment,' Information Systems Management, 26 (2), 123-137.

Doherty, NF., Marples, CG. and Suhaimi, A. (1999). 'The Relative Success of Alternative Approaches to Strategic Information Systems Planning: An Empirical Analysis,' Journal of Strategic Information Systems, 8 (3), 263-283.

Earl, M J. (1993) 'Experiences in Strategic Information Systems Planning, MIS Quarterly, 17 (1), 1-24.

Gartlan, J. and Shanks, G. (2007), 'The alignment of business and information technology strategy in Australia,' Australasian Journal of Information Systems, 14 (2), 113-138.

Gottschalk, P. (1999) 'Implementation Predictors of Strategy Information Systems Plans,' Information and Management, 36 (2), 77-91.

Griffiths, G. and Hackney, R. (2001), Strategic Information Systems for Competitive Advantage: Planning, Sustainability and Implementation, Strategic Information Technology: Opportunities for Competitive Advantage, Papp, R. (ed), Hershey, PA: Idea Group Publishing.

Grover, V. and Segars, AH. (2005), 'An Empirical Evaluation of Stages of Strategic
Information Systems Planning: Patterns of Process Design and Effectiveness,' Information and Management, 42 (5), 761779.

Hartono, E., Lederer, AL., Sethi, V. and Zhuang, Y. (2003), 'Key Predictors of the Implementation of Strategic Information Systems Plans,' The DATA BASE for Advances in Information Systems, 34 (3), 41-53.

ISACA., (2008), 'Top Business/Technology Issues Survey Results,' [Retrieved October 18, 2008], http://www.isaca.org/Template.cfm?Section =Homeandtemplate $=/$ ContentManagement $/$ Content

IT Governance Institute., (2003), 'Board briefing on IT governance (2nd ed.),' [Retrieved April 29, 2008], www.itgi.org

Jonkers, H., Lankhorst, MM., ter Doest, Hugo WL., Arbab, F., Bosma, H. and Wieringa, RJ. (2006), 'Enterprise architecture: Management tool and blueprint for the organization,' Information Systems Frontiers, 8 (2), 63-66.

King, W R. (2000) 'Assessing the efficacy of IS strategic planning,' Information Systems Management, 17 (1), 81-83.

Krell, K. and Matook, S. (2009), 'Competitive advantage from mandatory investments: An empirical study of Australian firms,' Journal of Strategic Information Systems, 18 (1), 3145.

Kunnathur, AS. and Shi, Z. (2001), 'An investigation of the strategic information systems planning success in Chinese publicly traded firms,' International Journal of Information Management, 21 (6), 423-439. 
Lederer, AL. and Sethi, V. (1988), 'The implementation of strategic information systems planning methodologies,' MIS Quarterly, 12 (3), 455-461.

Lee, J., Lee, C. and Jeong, KY. (2008), 'Governance Inhibitors in IT Strategy and Management: An Empirical Study of Korean Enterprises,' Global Economic Review, 37 (1), 1-22.

Luftman, JN., Kempaiah, R. and Rigoni, EH. (2009), 'Key Issues for IT Executives 2008,' MIS Quarterly Executive, 8 (3), 151-159.

Min, SK., Suh, EH. and Kim, SY. (1999), 'An integrated approach toward strategic information systems planning,' The Journal of Strategic Information Systems, 8 (4), 373-394.

Musson, D. (2009), IT Governance: A critical review of the literature, Information Technology Governance and Service Management: Frameworks and Adaptations, Information Science Reference, Cater-Steel, A. (ed), Hershey, New York, US.

NewKirk, HE. and Lederer, AL. (2006), 'The Effectiveness of Strategic Information Systems Planning Under Environmental Uncertainty,' Information and Systems, 43 (4), 481-501.

Newkirk, HE., Lederer, AL. and Johnson, AM. (2008), 'Rapid business and IT change: drivers for strategic information systems planning?' European Journal of Information Systems, 17 (3), 198-218.

Pai, J C. (2006) 'An empirical study of the relationship between knowledge sharing and IS/IT Strategic Planning (ISSP),' Management Decision, 44 (1), 105-122.
Palanisamy, R. (2005) 'Strategic Information Systems Planning Model for Building Flexibility and Success,' Industrial Management and Data Systems, 105 (1), 6381.

Pant, S. and Hsu, C. (1999), 'An Integrated Framework for Strategic Information Systems Planning and Development,' Information Resources Management Journal., 12 (1), 15-25.

Parfitt, M. and Tryfonas, T. (2009), 'Painless: A Model for IT Governance Assessment in the UK Public Sector,' EDPACS, 39 (2), 1-25.

Peterson, R R. (2004), Integration strategies and tactics for information technology governance, Strategies for Information Technology Governance, Van Grembergen, W. (ed), Hershey, PA: Idea Group Publishing.

Reich, BH. and Benbasat, I. (2000), 'Factors that influence the social dimension of alignment between business and information technology objectives,' MIS Quarterly, 24 (1), 81-111.

Segar, AH. and Grover, V. (1998), 'Strategic Information Systems Planning: An Investigation of the Construct and Its Measurement,' MIS Quarterly, 22 (2), 139163.

Sohal., AS. and Fitzpatrick, P. (2002), 'IT governance and management in large Australian organizations,' International Journal of Production Economics, 75 (1/2), 97-112.

Sugumaran, V. and Arogyaswamy, B. (2004), 'Measuring IT Performance: "Contingency" Variables and Value Modes,' Journal of Computer Information Systems, 44 (2), 79-86. 
Symons, C. (2005a), 'IT and Business Alignment - Are We There Yet?' Forrester Research, Inc., [Retrieved October 20, 2008], http://www.forrester.com

Symons, C. (2005b), 'IT governance framework: Structures, processes and communication,' Forrester Research, Inc., [Retrieved October 20, 2008], http://www.forrester.com

Teo, TSH. and Ang, JSK. (2000), 'How useful are strategic plans for information systems,' Behavior and Information Technology, 19 (4), 275-282.

Teo, TSH. and Ang, JSK. (2001), 'An examination of major IS planning problems,' International Journal of Information Management, 21 (6), 457-470.

Van Grembergen, W., De Haes, S. and Guldentops, E. (2004) Structures, processes and relational mechanisms for IT governance, Strategies for Information Technology Governance, Van Grembergen, W. (ed), Hershey, PA: Idea Group Publishing.

Wang, ETG. and Tai, JCF. (2003), 'Factors Affecting Information Systems Planning Effectiveness: Organizational Contexts and Planning Systems Dimensions,' Information and Management, 40 (4), 287-303.

Ward, J. and Peppard, V. (2002) Strategic Planning for Information Systems, $3^{\text {rd }}$ edition, John Wiley and Sons Ltd., England.

Webb, P., Pollard, C. and Ridley, G. (2006), 'Attempting to Define IT Governance: Wisdom or Folly?' Proceedings of the 39th Hawaii International Conference on System Sciences, 4-7 January 2006, Kauai, Hawaii.
Weill, P. and Ross, JW. (2004) IT Governance - How Top Performers Manage IT Decision Rights for Superior Results, Harvard Business School Press, Boston-Massachusetts.

Willson, P. and Pollard, C. (2009), 'Exploring IT Governance in Theory and Practice in a Large Multi-national Organization in Australia,' Information Systems Management, 26 (2), 98-109. 